\title{
Tradução transcultural do Minnesota Handwriting Assessment para o contexto brasileiro ${ }^{1}$
}

\author{
Adriane Guzman Pascullia ${ }^{a}$ Cynthia Yukiko Hiraga ${ }^{b}$, Ana Maria Pellegrini ${ }^{b}$ \\ a Universidade Estadual Paulista - UNESP, Rio Claro, SP, Brasil. \\ 'Instituto de Biociências, Universidade Estadual Paulista - UNESP, Rio Claro, SP, Brasil.
}

\begin{abstract}
Resumo: Introdução: A escrita é uma habilidade manual complexa e sua avaliação é um dos desafios encontrados pelos professores que atuam no processo de alfabetização. Objetivo: O presente estudo teve como objetivo validar e adaptar transculturalmente, para o contexto brasileiro, o Minnesota Handwriting Assessment (MHA), instrumento elaborado por Judith Reisman. Método: Participaram do estudo 448 crianças matriculadas nos $2^{\circ} \mathrm{e} 3^{\circ}$ anos do sistema público de ensino e duas professoras de escola que serviram como examinadoras. O método de validação utilizado foi o "Cross-Cultural Adaptation", e tal validação foi feita no estilo de escrita com letra bastão. Resultados: Em um primeiro momento, foi verificada a equivalência de conceitos, da semântica e a idiomática resultantes da tradução e retradução do MHA. A seguir, professoras aplicaram o instrumento traduzido e adaptado para a língua portuguesa. O coeficiente de correlação intraclasse (CCI) para fidedignidade teste-reteste foi 0,92 para legibilidade, 0,90 para forma, 0,99 para alinhamento e 0,89 para espaçamento, sendo significativo em todas as categorias. Com relação à fidedignidade entre avaliadores, o CCI foi 0,89 para legibilidade, 0,99 para alinhamento, 0,98 para tamanho $\mathrm{e}$ 0,90 para espaçamento, alcançando nível de significância em todas estas categorias. O CCI da categoria forma foi 0,53 , não atingindo nível de significância, resultado esse que pode estar relacionado à variabilidade do padrão da escrita manual apresentado pelas crianças brasileiras. Conclusão: A adaptação transcultural proposta e os resultados satisfatórios da validação do instrumento de avaliação da escrita em letra de bastão permite seu uso, com restrição da forma, no Sistema Educacional Brasileiro.
\end{abstract}

Palavras-chave: Escrita Manual, Adaptação Transcultural, Validação.

\section{Transcultural translation of the Minnesota Handwriting Assessment for the Brazilian context}

\begin{abstract}
Introduction: Writing is a complex human hand skill and its assessment is one of the several challenges encountered by teachers in the literacy process. Objective: The present study aimed to validate and adapt transculturally, for the Brazilian context, the Minnesota Handwriting Assessment ( $M H A)$, an instrument developed by Judith Reisman. Method: A total of 448 children enrolled in the 2 nd and 3rd school years from the public school system and two school teachers who served as examiners, participated in the present study. The validation method utilized was the "Cross-Cultural Adaptation" and it was applied for the validation of the D'Nealian style. Results: First, it was verified the equivalence of concepts, semantics and resulting idiomatic translation and retranslation of the $M H A$ to Portuguese language. Then, teachers were asked to use the adapted $M H A$ instrument. The Intraclass Correlation Coefficient (ICC) for the test-retest reliability was 0.92 for readability, 0.90 for form, 0.99 for alignment and 0.89 for spacing, being significant in all categories. About the inter-rater reliability, the ICC was 0.89 for readability, 0.99 for alignment, 0.98 for size, and 0.90 for spacing, reaching level of significance in these categories. The ICC 0.53 of form category did not reach level of significance what can be related to variability of the handwriting pattern of the Brazilian children. Conclusion: The cross-cultural adaptation for the Portuguese language and the satisfactory results obtained from the validation of the D'Nealian print style of handwriting assessment allowed its use in the Brazilian System of Education with restriction to the category of form.
\end{abstract}

Keywords: Handwriting, Cross-Cultural Adaptation, Validation.

Autor para correspondência: Adriane Guzman Pasculli, Universidade Estadual Paulista - UNESP, Avenida 24 A, 1515, Bela Vista, CEP 13506-900, Rio Claro, SP, Brasil, e-mail: dripasculli@yahoo.com.br

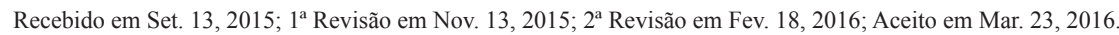




\section{Introdução}

Entre as diferentes produçôes humanas, a escrita se destaca por ser uma forma de comunicação importante no desenvolvimento humano, geralmente aprendida na infância, ao longo do processo de escolarização. É uma habilidade típica do ser humano, de grande valor social, cultural e acadêmico-escolar. É por meio da escrita que os seres humanos, ao longo do ciclo vital, registram seus pensamentos, suas emoçóes e todo um conjunto de atividades relacionadas com a aquisição do conhecimento e com a interação social (CALVO, 2007; TAM et al., 2009). O desenvolvimento da escrita começa com os primeiros rabiscos que se tornam, com o tempo, mais intencionais e mais precisos. As formas das letras podem ser vistas nos desenhos das crianças, indicando um aprendizado inicial da escrita (indicando início do processo de aprendizagem da escrita) (FEDER; MAJNEMER, 2007).

Com a aquisição da escrita manual, as crianças fazem uso dela de diferentes formas em função do contexto, como durante uma brincadeira, na comunicação, na expressão do pensamento. Nesse sentido, a escrita não deve ser considerada como mero instrumento de aprendizagem escolar, mas como elemento de produçáo intelectual e cultural, que possibilita a exploraçáo do ambiente e a comunicação com os demais participantes no contexto da sala de aula, explicitando os variados usos e funções que lhe são inerentes numa sociedade letrada e construída em ritmo pessoal (BRITO, 2007). Para a aquisição da escrita é preciso certo nível de desenvolvimento sensório-motor e cognitivo (FÁVERO, 2005; LE ROUX, 2005). Esta habilidade demanda coordenaçáo motora fina, esquema corporal, lateralidade, bem como organização espaço-temporal (FEDER; MAJNEMER, 2007).

A escrita manual é um tipo especial de atividade motora em que o escritor prepara e executa sequências específicas de padróes espaciais de deslocamento do lápis (MEULENBROEK; VAN GALEN, 1988), deixando registros no papel, e para as crianças em particular possibilita expressar, registrar e transmitir pensamentos e ideias. Ao longo dos anos um padrão pobre de desempenho do traçado da escrita da criança pode prejudicar o processo de aprendizagem acadêmica, dificultando a leitura, o desenvolvimento do raciocínio, com impacto negativo no acompanhamento do conteúdo sendo transmitido (MARTINS et al., 2013). Nesse contexto, a produção da escrita manual nos primeiros anos de escolarização deve ser uma temática abordada para a aquisição de uma escrita de qualidade.
A utilização de testes padronizados para avaliação da qualidade da escrita manual ou a observaçáo direta dos professores pode facilitar a identificação dos padróes de desempenho da escrita manual dos alunos. Tal avaliação é relevante, uma vez que a escrita manual é o instrumento que permite a avaliação da aquisição do conhecimento. De acordo com Racine et al. (2008), um instrumento de avaliaçáo padronizado, válido e confiável fornece pontuação quantitativa que permite ao avaliador medir a progressão do indivíduo ao longo do processo de aprendizagem. Entretanto, há uma carência no Brasil de métodos e instrumentos de avaliação no contexto da própria escola e em diferentes áreas, o que tem motivado pesquisadores a buscar tais ferramentas em outras línguas e culturas, que poderiam ser utilizadas após adaptação e validação ao contexto brasileiro. Segundo Fuentes, Mostofsky e Bastian (2009), o Minnesota Handwriting Assessment - MHA (REISMAN, 1999) é um instrumento de avaliação da escrita manual cujos resultados se aproximam dos relatos referentes à dificuldade de escrita apontada pelos professores das crianças. Consequentemente, tal instrumento pode ser visto como uma ferramenta fácil de administrar, podendo ser incorporada aos procedimentos utilizados pelos professores no processo de aquisição da escrita manual dos alunos. Assim, traduzir e adaptar transculturalmente para o contexto brasileiro o MHA (REISMAN, 1999) significa oferecer aos educadores e terapeutas, suporte seguro para avaliação da qualidade da escrita, fornecendo parâmetros para a prática profissional.

\subsection{Características gerais do Minnesota Handwriting Assessment (MHA)}

O MHA, elaborado por Reisman (1999), é um manual de Avaliação da Qualidade da Escrita em Língua Inglesa, que requer copiar, no estilo Palmer, Zaner-Bloser, ou D'Nealian, uma sentença impressa envolvendo todas as letras do alfabeto. Tendo sido elaborado no estado de Minnesota, nos Estados Unidos da América do Norte (EUA), utiliza formas caligráficas típicas daquele país.

Para avaliação da qualidade da escrita, de acordo com o protocolo do $M H A$, os participantes devem copiar, em letra bastáo ou cursiva, as palavras de um pangrama, que consiste em uma frase que transmite uma mensagem, com palavras que contêm, no seu conjunto, todas as letras (vogais e consoantes) do alfabeto da língua inglesa. O pangrama utilizado no $M H A$ foi "The quick brown fox jumps over the lazy dog"(Figura 1), elaborado e utilizado pela Microsoft 


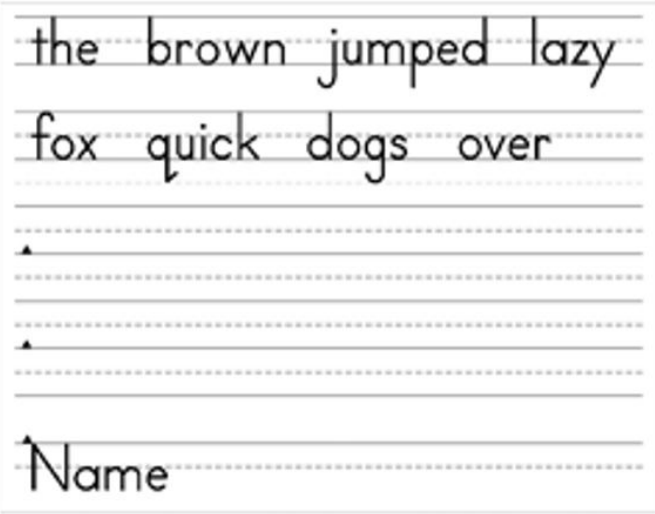

Figura 1. Modelo da folha de avaliação do $M H A$ (REISMAN, 1999). Fonte: Imagem extraída do site pearsonclinical ${ }^{2}$.

Word, podendo ser encontrado em softwares de edição de texto ou no editor de textos do Open Office.

\section{Objetivo Geral}

Validar o Minnesota Handwriting Assessment $M H A$ (REISMAN, 1999) para a língua portuguesa brasileira.

\subsection{Objetivos específicos}

- Adaptar transculturalmente o $M H A$ para a língua portuguesa brasileira.

- Verificar a fidedignidade teste-reteste do MHA adaptado para língua portuguesa brasileira.

- Verificar a fidedignidade entre avaliadores do $M H A$ adaptado para língua portuguesa brasileira.

\section{Método}

O estudo foi dividido em duas fases, sendo a primeira o "Cross-Cultural Adaptation", ou seja, o processo de tradução e retrotradução do $M H A$.

Autorização formal para tradução da língua inglesa para a portuguesa brasileira do $M H A$ e utilização no contexto brasileiro foram solicitadas à autora Judith Reisman (PASCULLI, 2014). A segunda fase consistiu na validação do $M H A$ (REISMAN, 1999) para a língua portuguesa e teve a participação de 448 crianças, na faixa etária de 6 a 8 anos, matriculadas nos segundos e terceiros anos do Ensino Fundamental de nove Escolas Municipais da cidade de Rio Claro, Estado de São Paulo. Ainda, duas professoras do ensino fundamental atuaram como avaliadoras usando o $M H A$ traduzido e adaptado ao contexto brasileiro.

Este projeto foi aprovado pelo Comitê de Ética em Pesquisa - seres humanos do Instituto de Biociências, Unesp, Rio Claro, processo 7166 e autorizado pela Secretaria da Educação do Município de Rio Claro. A participação de cada criança foi autorizada pelos pais ou responsáveis, mediante assinatura do Termo de Consentimento Livre e Esclarecido (TCLE). As duas professoras participantes também consentiram a participação no estudo assinando o TCLE.

A adequação cultural (tradução e retradução) do $M H A$ ao contexto brasileiro foi realizada a partir do método proposto por Beaton et al. (2000), descrito abaixo:

Tradução inicial: realização de duas traduçóes do instrumento, da linguagem original para a linguagem-alvo, ou seja, do inglês para o português, por dois tradutores independentes cuja língua materna era o português. Os tradutores náo tinham o conhecimento de que outro profissional simultaneamente estaria fazendo o mesmo trabalho.

Sintese das traduçóes: elaboração de síntese das traduçôes pelos responsáveis do projeto.

Retrotradução: com a versão consolidada em português, originada das duas traduções, foram realizadas duas retrotraduçóes do instrumento para a língua original, o inglês. Foram contratados outros dois tradutores juramentados, para verter novamente para o inglês as versóes anteriormente traduzidas para o português.

Comitê de Especialistas: participaram deste Comitê profissionais que atuavam no contexto escolar. O objetivo deste comitê foi elaborar a versão final do instrumento de avaliação da qualidade da escrita a partir das duas traduçóes e retrotraduçóes citadas anteriormente. Este comitê de especialistas foi composto por uma pedagoga, uma professora de Educação Física e uma terapeuta ocupacional.

Teste da versão final: o nível de entendimento dos avaliadores com relaçáo aos procedimentos para avaliação do instrumento foi verificado. A validação do instrumento $M H A$ adaptado foi realizada estimando a fidedignidade teste-reteste e fidedignidade entre avaliadores.

Após realizar a adequaçáo do $M H A$, os alunos realizaram a tarefa de transcrever um pangrama (i.e., sentença com todas as letras do alfabeto) em uma folha A4, como mostrado na Figura 2. Para este estudo foi utilizado o pangrama "um pequeno jabuti xereta viu dez cegonhas felizes” (WIKIPÉDIA, 2016). 
Calvo (2007) em seu estudo, que teve por objetivo verificar os efeitos de um programa de intervenção para crianças com dificuldades de escrita, baseado na variação da produção de força dos dedos, utilizou o mesmo pangrama. A tarefa foi realizada com todos os alunos de uma mesma sala, sentados em suas carteiras. Para cada um dos alunos foi fornecido lápis preto e uma folha de avaliação. A seguir, as avaliaçôes das 448 crianças foram analisadas por duas avaliadoras (i.e., professoras do ensino fundamental) a partir da versão traduzida para o português do $M H A$. As avaliadoras analisaram novamente as avaliações após quinze dias da primeira análise, sendo 50 avaliaçôes escolhidas ao acaso do total aplicado. Destas análises foi realizada a verificação da fidedignidade teste-reteste e fidedignidade Inter e Intra-avaliadores por meio do Coeficiente de Correlação Intraclasse (CCI). O CCI é uma ferramenta estatística utilizada para mensurar a fidedignidade de medidas, podendo mensurar a homogeneidade de duas ou mais medidas. O CCI

\section{PEQUENO VIU XERETA FELIZES UM CEGONHAS JABUTI DEZ}

\section{NOME}

Figura 2. Folha de avaliação da qualidade da escrita manual em letra bastão. Fonte: Pasculli (2014). é uma estimativa da fração da variabilidade total de medidas devido a variaçóes entre os indivíduos (MATTA, 2010). De acordo com a literatura, quando o valor do CCI é menor que 0,4 , há uma baixa reprodutibilidade, e quando está no intervalo entre 0,4 e 0,75 , a reprodutibilidade é satisfatória, e quando os valores são acima de 0,75 , a reprodutibilidade é excelente (MATTA, 2010; THOMAS; NELSON, 2002; THOMAS; NELSON; SILVERMAN, 2012).

Para o presente estudo, apenas a letra bastão foi utilizada, tendo em vista o contexto educacional brasileiro. A partir de 2005, por meio da Lei n ${ }^{\circ} 11.114 / 05$ do Ministério da Educação (BRASIL, 2005), as crianças devem ingressar no ensino fundamental aos 6 anos de idade, e o ensino brasileiro foi estendido para educação em nove anos; com isso, algumas crianças no terceiro ano estáo iniciando a aquisição da escrita cursiva, apresentando assim grande variação de desempenho para esse tipo de letra. No protocolo original, a autora realizou a pesquisa com os $1^{\circ}$ e $2^{\circ}$ anos, entretanto, devido à alteraçáo na educação brasileira, foi realizada a pesquisa com os $2^{\circ}$ e $3^{\circ}$ anos. A pauta da folha de avaliaçáo foi adaptada em relaçáo à versáo em inglês do $M H A$ de $0,9 \mathrm{~cm}$ para $0,6 \mathrm{~cm}$, buscando aproximação com o tamanho das pautas dos cadernos brasileiros.

As categorias de qualidade do $M H A$ foram adaptadas anteriormente por Calvo (2007) em relaçáo aos aspectos qualitativos da escrita manual e o desempenho quanto à legibilidade, forma, alinhamento das letras e espaçamento entre as letras e palavras. É apresentada na Tabela 1 uma breve descrição dos critérios de avaliação da qualidade da escrita, utilizados por Calvo (2007).

Tabela 1. Descrição dos critérios de avaliação da qualidade da escrita.

\begin{tabular}{ll}
\hline \multicolumn{1}{c}{$\begin{array}{c}\text { CATEGORIAS DE } \\
\text { QUALIDADE }\end{array}$} & \multicolumn{1}{c}{ DESCRIÇÃo } \\
\hline LEGIBILIDADE & $\begin{array}{l}\text { Diz respeito à capacidade de identificar e interpretar o símbolo (letra) produzido por } \\
\text { uma combinação de traços. }\end{array}$ \\
\hline FORMA & $\begin{array}{l}\text { Diz respeito às características dos traços do símbolo (letra), como proporcionalidade } \\
\text { e nitidez dos traçados. }\end{array}$ \\
\hline TAMANHO & $\begin{array}{l}\text { Diz respeito à produção das letras acompanharem ou não todas as linhas de referência, } \\
\text { com exceção da linha de base. Respeitar as linhas da pauta garante que o tamanho das } \\
\text { letras seja preservado. Assim, cada letra foi avaliada levando em conta as dimensões } \\
\text { verticais. Foi considerada a altura das letras em relação às linhas. }\end{array}$ \\
\hline ALINHAMENTO & $\begin{array}{l}\text { Diz respeito aos traçados das letras acompanharem a linha principal da pauta, e as letras } \\
\text { que flutuam sobre a linha caracterizam erros de alinhamento em relação à pauta principal. }\end{array}$ \\
\hline ESPAÇAMENTO & $\begin{array}{l}\text { Diz respeito ao espaço entre letras e palavras. Para medir os espaços entre as letras e } \\
\text { palavras da frase, foi adotado o ponto mais à direita da primeira letra (ou palavra) e o } \\
\text { ponto mais à esquerda da próxima letra (ou palavra). }\end{array}$ \\
\hline
\end{tabular}

Fonte: Calvo (2007). 
Uma letra ilegível, não identificada, recebeu um ponto de erro para cada uma das cinco categorias de qualidade. A partir dos critérios de avaliaçáo de cada uma das categorias citadas acima é atribuído um ponto para cada erro detectado, podendo atingir, por categoria, o máximo de 35 erros no conjunto das palavras. Cada letra poderá receber somente um ponto de erro em cada variável, mesmo que, com base nos critérios, fossem várias as infraçôes/erros. Assim, ao final é descontado do número total de letras a quantidade de erros (REISMAN, 1999).

A pontuação máxima também foi adaptada de 35 para 42 letras, uma vez que o conjunto de palavras da frase em inglês tem 35 letras e em português, 42 letras. No MHA, o tempo da escrita da frase em segundos é obtido pela divisão da quantidade de letras copiadas por 150 segundos, ou seja, pelo período de 2'30" (dois minutos e trinta segundos) de execução da tarefa. O tempo da escrita da frase em português também foi adaptado, sendo adequado proporcionalmente para a execução de 42 letras. $\mathrm{O}$ período estipulado para a execuçáo da tarefa foi de 3'05” (três minutos e cinco segundos).

\section{Análise de Dados}

Para a análise do processo de tradução e retrotradução, os dados foram analisados por meio de reunióes com o comitê de especialistas para consolidar todas as versôes das traduçôes, e desenvolver a versão final do instrumento que foi considerada, verificando a equivalência e a qualidade da tradução. Quando se fez necessário, foi realizado contato com os tradutores para obtençáo de um consenso dos termos utilizados. Assim, os avaliadores consideraram a equivalência de conceitos, semântica e idiomática (BEATON et al., 2000). As discussóes e consensos acerca dos termos resultaram em adequaçóes das palavras, que buscaram retratar, com precisão, a justificativa para cada termo adotado. As discussóes e consensos dos termos foram apresentadas em relatórios sistematizados descritivamente, buscando retratar com precisão a justificativa para cada termo adotado.

Para análise dos dados coletados nas escolas foi realizada a verificação da fidedignidade teste-reteste e fidedignidade Inter e Intra-avaliadores. Primeiramente, dois avaliadores foram treinados através de dez avaliaçôes. Após esta etapa, os avaliadores analisaram as 448 folhas com o pangrama reproduzido pelos alunos participantes do presente estudo. Para cada item foi aceito o nível de concordância de $90 \%$ entre avaliadores. Os itens que não atingiram este percentual foram reavaliados. Após um período aproximado de 15 dias da entrega da primeira avaliação, foram sorteadas, pela pesquisadora, 50 avaliaçóes para os dois avaliadores reavaliarem. Estabeleceu-se como prazo para devolução da segunda avaliação sete dias. A verificaçáo da fidedignidade do instrumento foi feita pelo Coeficiente de Correlação Intraclasse (CCI). Para o teste estatístico adotou-se o intervalo de confiabilidade de $90 \%$. O programa estatístico utilizado foi o IBM SPSS Statistic para Windows, versão 21 (2012).

\section{Resultados}

As pesquisadoras responsáveis pelo estudo realizaram a síntese das traduçóes elaboradas pelos tradutores. O primeiro tradutor apresentou uma tradução mais literal das palavras. Em contrapartida, o segundo tradutor possuía conhecimento dos conceitos examinados no instrumento de avaliação que estava sendo traduzido e sua tradução apresentou uma equivalência maior com o contexto real.

A tradução do $M H A$ para a língua portuguesa foi feita por meio da técnica da tradução invertida, que envolve quatro tradutores. Dois tradutores bilíngues realizaram a tradução do instrumento da língua inglesa para a língua portuguesa. Resultou em duas traduçōes independentes, bastante próximas, mas não exatamente iguais. As duas traduçôes foram transformadas em um único documento, a partir de análise e consenso do comitê de especialistas. A versão em português foi convertida para a língua inglesa por outros dois tradutores, sem a ajuda da versáo original. Foram obtidas, portanto, quatro versóes, duas na língua portuguesa e duas na língua inglesa. Após a tradução inversa, realizaram-se a avaliação e a modificação das versôes preliminares.

O comitê de especialistas se reuniu para avaliar as modificaçóes das versôes preliminares. As duas traduçôes para a língua inglesa foram comparadas com a versão original do instrumento, a semântica das questóes foi mantida, e as poucas mudanças necessárias restringiram-se à substituição de palavras pouco usadas por sinônimos mais frequentes. As duas versóes na língua portuguesa foram revisadas. Correçôes em relação aos termos técnicos utilizados na tradução e adequação dos critérios para a compreensão pelo público-alvo foram o foco das discussões do comitê. As versóes em língua portuguesa foram adaptadas e unificadas, resultando na versão final do instrumento.

Para que o pangrama fosse adequado ao estudo, a frase deveria apresentar o menor número de repetições. Nesse trabalho, das 42 letras que compóem o pangrama, 13 letras delas aparecem apenas uma 
vez e 9 letras repetem duas ou mais vezes. As letras vogais, que são letras de ligação, aparecem mais que as letras consoantes. Das repetiçôes, a letra "E" é a que apresenta o maior número de repetiçóes, com 19.1\%. Cada uma das letras "N", "O", "S", "T", "Z" representam $4.7 \%$ do total das repetiçóes, aparecendo duas vezes na frase. A quantidade e a frequência de repetição das letras na frase é apresentada na Tabela 2.

De acordo com o manual de Avaliação da Qualidade da Escrita Manual (REISMAN, 1999), cada letra deve ser avaliada a partir de cada categoria de qualidade. Assim, cada letra apresenta uma quantidade variada de possibilidades de erro por categoria. No caso da categoria legibilidade, há 10 possibilidades de erro, entretanto, a maioria das letras tem a possibilidade de ter de seis a sete itens considerados como possibilidade de erro, com exceção da letra "J", que tem nove, letra "P" com oito e a letra "X" com cinco possibilidades de erro. Para a categoria forma, das 11 possibilidades de erro, a maioria das letras apresenta de quatro a seis possibilidades de erro, com exceção da letra "I",

Tabela 2. Frequência de cada uma das letras do alfabeto presentes na frase utilizada neste estudo.

\begin{tabular}{ccc}
\hline Letras & $\begin{array}{c}\text { Frequência total } \\
\text { de cada uma das } \\
\text { letras na frase }\end{array}$ & $\begin{array}{c}\text { Frequência relativa } \\
\text { das letras } \\
(\mathbf{n}=42)\end{array}$ \\
\hline A & 3 & 7,1 \\
B & 1 & 2,4 \\
C & 1 & 2,4 \\
D & 1 & 2,4 \\
E & 8 & 19,1 \\
F & 1 & 2,4 \\
G & 1 & 2,4 \\
H & 1 & 2,4 \\
I & 3 & 7,1 \\
J & 1 & 2,4 \\
L & 1 & 2,4 \\
M & 1 & 2,4 \\
N & 2 & 4,7 \\
O & 2 & 4,7 \\
P & 1 & 2,4 \\
Q & 1 & 2,4 \\
R & 1 & 2,4 \\
S & 2 & 4,7 \\
T & 2 & 4,7 \\
U & 4 & 9,6 \\
V & 1 & 2,4 \\
X & 1 & 2,4 \\
Z & 2 & 4,7 \\
23 & 42 & 100 \\
\hline Fonte: Elaborado pela autora. &
\end{tabular}

Fonte: Elaborado pela autora. que apresenta três itens de possibilidades de erro. $\mathrm{Na}$ categoria alinhamento das três possibilidades, todas as letras podem ter apenas uma possibilidade de erro. Para tamanho, todas as letras apresentam apenas uma possibilidade de erro, e para espaçamento dos dois itens; as letras apresentam uma ou duas possibilidades de erro, com exceçâo das letras "P" e "U”, que não se enquadram no item por não terem uma letra anterior para cálculo do espaçamento. A quantidade de subitens de possibilidade de erros por letra em cada categoria é apresentada na Tabela 3.

\subsection{Fidedignidade teste-reteste}

Com a verificação da fidedignidade através do teste-reteste, os dados da primeira avaliação foram comparados com os dados da segunda avaliação realizada pelo mesmo avaliador, após um período de 15 dias entre as avaliaçóes. Os resultados da fidedignidade são apresentados de acordo com cada uma das cinco categorias de qualidade da escrita manual.

Com relação a pontuaçóes totais no teste-reteste (Tabela 4), o CCI obtido foi de 0,92 para legibilidade, 0,99 para forma e alinhamento, 0,89 para tamanho e 0,80 para espaçamento. De acordo com os resultados apresentados no teste-reteste, os valores obtidos foram significativos.

\subsection{Fidedignidade entre avaliadores}

A fidedignidade entre avaliadores tem como finalidade verificar em que grau diferentes avaliadores podem obter o mesmo resultado a partir dos mesmos dados (THOMAS; NELSON; SILVERMAN, 2012). Para verificação da fidedignidade, os dados foram avaliados por dois avaliadores independentes. Os resultados da fidedignidade são apresentados de acordo com cada uma das cinco categorias de qualidade da escrita manual. A verificação da fidedignidade do instrumento foi realizada com base no Coeficiente de Correlação Intraclasse (CCI). Para o teste estatístico foi adotado o intervalo de confiabilidade de $90 \%$.

Conforme a Tabela 4, considerando as pontuaçóes totais para legibilidade apresentadas pelas duas avaliadoras, o CCI foi de 0,89 . Com relação à categoria de qualidade forma, o valor de CCI foi de 0,53 , náo alcançando nível de significância. $\mathrm{Na}$ categoria de qualidade alinhamento, o valor de CCI foi de 0,99, na categoria de qualidade tamanho, o valor de CCI foi de 0,98 e na categoria de qualidade espaçamento, o valor de CCI foi de 0,90 , portanto, com resultados todos eles significativos. 
Tabela 3. Quantidade de itens de possibilidade de erros por letra em cada categoria.

\begin{tabular}{cccccc}
\hline Letras & $\begin{array}{c}\text { Erros em } \\
\text { legibilidade por } \\
\text { letra }\end{array}$ & $\begin{array}{c}\text { Erros em forma } \\
\text { por letra }\end{array}$ & $\begin{array}{c}\text { Erros em } \\
\text { alinhamento } \\
\text { por letra }\end{array}$ & $\begin{array}{c}\text { Erros em } \\
\text { tamanho por } \\
\text { letra }\end{array}$ & $\begin{array}{c}\text { Erros em } \\
\text { espaçamento } \\
\text { por letra }\end{array}$ \\
\hline A & 6 & 4 & 1 & 1 & 1 \\
B & 6 & 6 & 1 & 1 & 1 \\
C & 7 & 5 & 1 & 1 & 2 \\
D & 7 & 6 & 1 & 1 & 2 \\
E & 7 & 4 & 1 & 1 & 1 \\
F & 7 & 4 & 1 & 1 & 2 \\
G & 7 & 6 & 1 & 1 & 1 \\
H & 6 & 4 & 1 & 1 & 1 \\
I & 7 & 3 & 1 & 1 & 1 \\
J & 9 & 4 & 1 & 1 & 2 \\
L & 7 & 4 & 1 & 1 & 1 \\
M & 6 & 4 & 1 & 1 & 1 \\
N & 7 & 4 & 1 & 1 & 1 \\
O & 6 & 4 & 1 & 1 & 1 \\
P & 8 & 6 & 1 & 1 & 0 \\
Q & 7 & 4 & 1 & 1 & 1 \\
R & 7 & 6 & 1 & 1 & 1 \\
S & 7 & 4 & 1 & 1 & 1 \\
T & 7 & 6 & 1 & 1 & 1 \\
U & 6 & 4 & 1 & 1 & 0 \\
V & 6 & 4 & 1 & 1 & 2 \\
X & 5 & 5 & 1 & 1 & 2 \\
Z & 7 & 4 & 1 & 1 & 1 \\
\hline
\end{tabular}

Fonte: Elaborado pela autora.

Tabela 4. Coeficiente de Correlação Intraclasse por categoria no teste-reteste e entre avaliadores.

\begin{tabular}{lcc}
\hline \multicolumn{1}{c}{ Categoria } & $\begin{array}{c}\text { Avaliação da Fidedignidade } \\
\text { Teste-Reteste por categoria } \\
\text { (Intervalo de Confiança 90\%) }\end{array}$ & $\begin{array}{c}\text { Avaliação da Fidedignidade entre } \\
\text { avaliadores por categoria } \\
\text { (Intervalo de Confiança 90\%) }\end{array}$ \\
\hline Legibilidade & $0,92^{*}$ & $0,89^{*}$ \\
Forma & $0,99^{*}$ & 0,53 \\
Alinhamento & $0,99^{*}$ & $0,99^{*}$ \\
Tamanho & $0,89^{*}$ & $0,98^{*}$ \\
Espaçamento & $0,80^{*}$ & $0,90^{*}$ \\
\hline
\end{tabular}

Fonte: Elaborado pela autora. Nota: O símbolo * representa os valores que atingiram nível de significância.

\section{Discussão}

A escrita manual é uma importante ferramenta no registro de informação de interesse do sujeito, possibilitando interação e generalização dos elementos centrais que subsidiam esta habilidade típica do ser humano. No contexto brasileiro, não contamos com nenhum instrumento de avaliação da escrita manual que subsidie esta atividade no contexto educacional.

O processo de retrotradução possibilita não só validar a tradução feita, mas também oferecer subsídios para a correçáo de erros que possam estar relacionados à traduçâo literal propriamente dita ou a qualquer interpretação embutida nos termos traduzidos (MININEL, 2010). É importante salientar que a literatura traz autores que apontam diferentes procedimentos para adaptação transcultural de um instrumento de avaliaçấo para uma outra cultura (GUILLEMIN, 1995; BEATON et al., 2000; MANEESRIWONGUL; DIXOX, 2004). Segundo Teixeira et al. (2011), é de suma importância que as etapas do processo de adaptação transcultural sejam rigorosamente descritas, garantindo a fidedignidade dos resultados para o estudo.

Para interpretação dos valores obtidos, os valores acima de 0,75 foram considerados como bons, e os 
valores abaixo de 0,75 de pobre para moderado, de acordo com o proposto por Portney e Watkins (2000). Segundo ainda esses autores, a interpretação é apenas uma sugestão, cabendo aos autores do estudo julgar a confiabilidade e o grau de aceitação do instrumento.

No presente estudo foram adotados os critérios propostos por Portney e Watkins (2000), com as alteraçôes sugeridas por Iwamizu (2013), que, em seu estudo, considerou para validação dos resultados os valores acima de 0,75 como bons, de 0,50 a 0,75 como moderados e abaixo de 0,50 como 'pobres'. Assim, o CCI para fidedignidade teste-reteste foi de 0,92 para legibilidade, 0,90 para forma, 0,99 para alinhamento e 0,89 para espaçamento, significativos em todas as categorias, ou seja, legibilidade, forma, tamanho, alinhamento e espaçamento. Com relaçáo à fidedignidade entre avaliadores, o CCI foi de 0,89 para legibilidade, 0,53 para forma, 0,99 para alinhamento, 0,98 para tamanho e 0,90 para espaçamento, alcançando nível de significância nas categorias legibilidade, tamanho, alinhamento e espaçamento, com exceção da categoria forma, que alcançou o CCI de 0,53 , considerado como moderado. Este resultado pode ser devido ao processo cognitivo e motor para aquisição e consolidaçáo do traçado da escrita. Outro fator relevante e apontado na literatura diz respeito à inconsistência nas relaçôes entre leitura e escrita nos estágios iniciais da alfabetização (SOUSA; MALUF, 2004). Conforme as autoras, quando as crianças começam a utilizar estratégias ortográficas de leitura e de escrita no processo da alfabetização, a habilidade de leitura é melhor do que a da escrita. Nesse contexto, é possível que a produção do traçado, particularmente a forma, apresente maior variabilidade na produção das letras do alfabeto.

A partir dos resultados obtidos no presente estudo, pode-se concluir que processo de adaptação transcultural da versão brasileira proposta do instrumento de avaliação da qualidade da escrita está em condição de ser recomendada para aplicação. Os resultados da avaliaçấo da qualidade de escrita manual apresentaram valores que atingiram nível de significância, assim, podem ser considerados adequados para uso no contexto educacional. Entretanto, análises da escrita manual cursiva também são necessárias.

\section{Conclusão}

Poucos estudos são realizados na educação sobre o ensino e as formas básicas da escrita manual. A falta de modelo e padrão, assim como a falta de referencial que pudesse nortear os trabalhos na educação, prejudicam os passos que devem ser dados para ter uma educação com qualidade. Ainda que esses trabalhos sejam limitados, em termos de referencial teórico, eles indicam a necessidade de valorizar empreendimentos nesse setor, uma vez que afetam diretamente a prática escolar.

Tendo em vista a diversidade do povo brasileiro, em função do tamanho do território nacional e da variabilidade de culturas que se inserem, com influência europeia, americana, portuguesa, espanhola, entre outras culturas, isso faz do Brasil um país único, com uma distância entre a realidade brasileira e de outros países. Assim, considera-se de extrema importância a avaliação da qualidade da escrita das crianças no processo de alfabetizaçáo no contexto escolar através de instrumento padronizado que permita comparar a capacidade de comunicaçáo escrita dos alunos neste nível de ensino no sistema educacional como um todo.

O presente estudo teve como objetivo principal traduzir, adaptar e validar para o contexto brasileiro o Minnesota Handwriting Assessment (REISMAN, 1999). Em específico, teve como objetivos verificar a fidedignidade teste-reteste e entre avaliadores no contexto brasileiro. Os resultados relativos, tanto da validação da tradução como da adaptaçáo transcultural do instrumento de avaliação da qualidade da escrita manual, foram considerados satisfatórios. A discussão e análise dos dados advindos da retrotradução elucidaram alguns termos dúbios que haviam sido discutidos durante a síntese das traduçôes, devido à dificuldade de clareza do significado diante do contexto. Em torno de 50 termos tiveram que ser adaptados ao contexto brasileiro, termos estes que apresentaram correspondência quando da retrotradução para o inglês, o que implicou alteraçôes na versão elaborada. Convém realçar que poucas foram as alteraçóes sugeridas, diante da quantidade de termos que constituem o instrumento no texto original.

Neste sentido, pode-se afirmar que a adaptação para o contexto brasileiro do $M H A$ poderá ser útil para futuras análises da escrita manual. A avaliação da qualidade da escrita manual é um dos passos que deve conduzir a educação brasileira para melhoria no processo ensino-aprendizagem ao longo do processo de escolarização. Na medida em que tivermos um instrumento de avaliação da escrita manual sendo utilizado pelos professores, poderemos entáo rever o processo de ensino dessa escrita. A falta de padróes e modelos na educação brasileira prejudica a aquisiçáo de uma escrita com qualidade. Por outro lado, este estudo mostra a possibilidade de buscar um padrão com qualidade para as crianças por meio das avaliações. 


\section{Referências}

BEATON, D. E. et al. Guidelines for the process of cross-cultural adaptation of self-report measures. Spine, London, v. 25, n. 24, p. 3186-3191, 2000.

BRASIL. Lei no 11.114 , de 16 de maio de 2005. Altera os arts. 6, 30, 32 e 87 da Lei n ${ }^{\circ} 9.394$, de 20 de dezembro de 1996, com o objetivo de tornar obrigatório o início do ensino fundamental aos seis anos de idade. Diário Oficial [da] República Federativa do Brasil, Brasília, DF, 17 maio 2005. Disponível em: <https://www.planalto. gov.br/ccivil_03/_Ato2004-2006/2005/Lei/L11114. htm>. Acesso em: 01 jan. 2014.

BRITO, A. E. Prática pedagógica alfabetizadora: a aquisição da língua escrita como processo sociocultural. Revista Iberoamericana de Educación, Argentina, v. 4, n. 44, p. 1-9, 2007.

CALVO, A. P. A produção gráfica e escrita focalizando a variação da produção de força dos dedos. 2007. $191 \mathrm{f}$. Dissertaçáo (Mestrado em Ciências da Motricidade) - Universidade Estadual Paulista, Rio Claro, 2007.

FÁVERO, M. T. M. Desenvolvimento psicomotor e aprendizagem da escrita. 2005. 162 f. Dissertação (Mestrado em Aprendizagem e Ação do Docente) - Universidade Estadual de Maringá, Maringá, 2005.

FEDER, K. P.; MAJNEMER, A. Handwriting development, competency, and intervention. Developmental Medicine \& Child Neurology, Malden, v. 49, n. 4, p. 312-317, 2007.

FUENTES, C. T.; MOSTOFSKY, S. H.; BASTIAN, A. J. Children with autism show specific handwriting impairments. Neurology, Minneapolis, v. 73, n. 19, p. 1532-1537, 2009.

GUILLEMIN, F. Cross-cultural adaptation and validation of health status measures. Scandinavian Journal of Rhematology, Norrebrogade, v. 24, n. 2, p. 61-63, 1995.

IWAMIZU, J. S. Tradução, adaptação transcultural, validação e fidedignidade de um instrumento para identificação do perfil motor de crianças entre 3 e 5 anos de idade. 2013. 122 f. Dissertação (Mestrado em Ciências) - Universidade de São Paulo, São Paulo, 2013.

LE ROUX, Y. Apprentissage de L'écritureetpsychomotricité. Marseille: Solal, 2005.

MANEESRIWONGUL, W.; DIXON, J. K. Instrument translation process: a methods review. Journal of Advanced Nursing, Oxford, v. 48, n. 2, p. 175-186, 2004.

MARTINS, M. R. I. et al. Rastreio de disgrafia motora em escolares da rede pública de ensino. Jornal de Pediatria, Rio de Janeiro, v. 89, n. 1, p. 70-74, 2013.

MATTA, S. R. Adaptação transcultural de instrumento para medida da adesäo ao tratamento anti-hipertensivo e antidiabético. 2010. 88 f. Dissertaçấo (Mestrado em Ciências) - Escola Nacional de Saúde Pública Sergio Arouca, Rio de Janeiro, 2010.

MEULENBROEK, R. G. J.; VAN GALEN, G. P. The Acquisition of skilled handwriting: discontinuous trends in kinematic variables. In: COLLEY, A. M.; BEECH, J. R. Advances in Psychology. Oxford: North-Holland, 1988. p. 273-281.

MININEL, V. A. Adaptação transcultural do Work Disability Diagnosis Interview (WOODI) para o contexto brasileiro. 2010. 188 f. Tese (Doutorado em Ciência) Universidade de São Paulo, São Paulo, 2010.

PASCULLI, A. G. Tradução e adaptação transcultural do Minnesota Handwriting Assessment para aplicação no Brasil. 2014. 127 f. Dissertaçáo (Mestrado em Desenvolvimento Humano e Tecnologias) - Universidade Estadual Paulista Júlio de Mesquita Filho, Rio Claro, 2014.

PEARSON CLINICAL BRASIL. São Paulo, 2015. Disponível em: <www.pearsonclinical.com.br>. Acesso em: 13 set. 2015.

PORTNEY, L.; WATKINS, M. Foundations of clinical research: applications to practice. New Jersey: Prentice Hall Health, 2000

RACINE, M. B. et al. Handwriting performance in children with attention deficit hyperactivity disorder (ADHD). Journal of Child Neurology, Thousand Oaks, v. 23, n. 4, p. 399-406, 2008.

REISMAN, J. Minnesota handwriting assessment manual. San Antonio: Harcourt Assessment Inc, 1999.

SOUSA, É. D. O.; MALUF, M. R. Habilidades de leitura e de escrita no início da escolarização. Psicologia da Educação, São Paulo, v. 19, p. 55-72, 2004.

TAM, C. et al. Rater reliability of the adapted scoring criteria of the Minnesota Handwriting Assessment for children with cerebral palsy. Australian Occupational Therapy Journal, Melbourne, v. 56, n. 6, p. 403-408, 2009.

TEIXEIRA, P. C. et al. Adaptação transcultural: tradução e validação de conteúdo da versão brasileira do Commitment Exercise Scale. Archives of Clinical Psychiatry, Sáo Paulo, v. 38, n. 1, p. 24-28, 2011.

THOMAS, J. R.; NELSON, J. K. Métodos de pesquisa em atividade fisica. Porto Alegre: Artmed, 2002.

THOMAS, J. R.; NELSON, J. K.; SILVERMAN, S. Métodos de pesquisa em atividade fisica. Porto Alegre: Artmed, 2012.

WIKIPÉDIA. Pangrama. Disponível em: <https:// pt.wikipedia.org/wiki/Pangrama $>$. Acesso em: $8 \mathrm{dez}$. 2016. 


\section{Contribuição dos Autores}

Adriane e Cynthia participaram da concepção do projeto, coleta e análise dos dados e redação do texto. Ana Maria Pellegrini participou de todas as etapas supracitadas, além da revisão do texto. Todos os autores aprovaram a versão final do texto.

\section{Notas}

${ }^{1} \mathrm{O}$ artigo é parte da dissertação, em nível de Mestrado, apresentada ao Programa de Pós-graduação em Desenvolvimento Humano e Tecnologias, Instituto de Biociências, Universidade Estadual Paulista Júlio de Mesquita Filho - UNESP/Rio Claro - SP, intitulada "Traduçâo e Adaptação Transcultural do Minnesota Handwriting Assessment para Aplicação no Brasil”, de Adriane Guzman Pasculli. O projeto de pesquisa foi aprovado pelo Comitê de Ética em Pesquisa em Seres Humanos do Instituto de Biociências, UNESP/RC, conforme protocolo 7166.

${ }^{2}$ Endereço Eletrônico da Imagem: Pearson Clinical Brasil (2015). 